\title{
BK Virus in Allogeneic and Autologous Bone Marrow Transplantation: Review Article
}

\author{
Ilhami BERBER ${ }^{1, *}$, Mehmet Ali ERKURT ${ }^{1}$, Funda YETKIN ${ }^{2}$, Irfan KUKU ${ }^{1}$, Emin KAYA ${ }^{1}$, Emin BODAKCI ${ }^{3}$, \\ Mustafa KOROGLU ${ }^{1}$, Ilknur NIZAM ${ }^{1}$ \\ ${ }^{1}$ Department of Hematology, Bone Marrow Transplantation Unit, Faculty of Medicine, Inonu University, Malatya, Turkey \\ ${ }^{2}$ Department of Infection Disease, Faculty of Medicine, Inonu University, Malatya, Turkey \\ ${ }^{3}$ Department of Internal Medicine, Faculty of Medicine, Inonu University, Malatya, Turkey \\ *Corresponding author: drilhamiberber@hotmail.com
}

Received September 10, 2014; Revised September 17, 2014; Accepted September 21, 2014

\begin{abstract}
The BK virus is a member of the polyomavirus family. When the immune system is compromised, as in patients undergoing chemotherapy after hematopoietic stem cell and solid organ transplantation, the virus is reactivated, leading to haemorrhagic cystitis. While the BK virus is one of the most common causes of morbidity and mortality in patients after allogeneic stem cell transplantation, it rarely occurs after autologous stem cell transplantation. The early diagnosis and treatment of viral cystitis may prevent significant morbidity and mortality associated with haemorrhagic cystitis caused by the BK virus. It is not entirely clear how the BK virus affects prognosis in patients undergoing allogeneic and autologous hematopoietic stem cell transplantation.
\end{abstract}

Keywords: BK Virus, Allogeneic and Autologous Bone Marrow Transplantation

Cite This Article: Ilhami BERBER, Mehmet Ali ERKURT, Funda YETKIN, Irfan KUKU, Emin KAYA, Emin BODAKCI, Mustafa KOROGLU, and Ilknur NIZAM, "BK Virus in Allogeneic and Autologous Bone Marrow Transplantation: Review Article.” American Journal of Medical Sciences and Medicine, vol. 2, no. 5 (2014): 85-88. doi: 10.12691/ajmsm-2-5-1.

\section{Introduction}

The BK virus (BKV) was first isolated as a new human papovavirus from the urine of a renal transplant patient by Gardner et al. in 1971. Polyomavirus hominis 1 (genus Polyomaviridae), the BKV, is a non-encapsulated DNA virus that is highly prevalent in healthy adults, with up to $90 \%$ seropositivity. Past infection with the BKV is common, but significant consequences of the infection are uncommon. In contrast, the BKV frequently causes mortality and morbidity in immunocompromised and immunosuppressed patients, and it can also be identified in the non-transplant setting in patients with B-cell lymphoproliferative disorders [1].

The BKV is a well-known cause of graft dysfunction following renal transplantation and it has been reported in the native kidneys of other solid organ recipients. BKV infection has been connected with the development of haemorrhagic cystitis (HC) after allogeneic transplant; it occurs in up to $70 \%$ of hematopoietic stem cell transplant (HSCT) recipients and is associated with prolonged hospitalisation [2]. However, HC caused by BKV rarely occurs in autologous HSCT [3]. This virus can be diagnosed by a BKV blood test or a urine test for decoy cells. Polymerase chain reaction (PCR) techniques are often carried out to identify the virus [4].

The cornerstone of therapy is the reduction of immunosuppression. A recent surge in BKV nephropathy correlates with the use of potent immunosuppressant drugs [5]. Topical anaesthetics such as phenazopyridine, antispasmodic agents, and narcotic analgesics can use in treatment of HC [6,7]. Insertion of a large-bore three-way Foley's urethral catheter to decompress the bladder and saline solution irrigation of the bladder is recommended for HC [8]. However, no drug is yet licensed for use in $\mathrm{BKV}$ infection. Other therapeutic options include cidofovir, leflunomide, intravenous immunoglobulin (IVIG), fluoroquinolones, hyperbaric oxygen, and cytotoxic T lymphocytes [9,10,11,12,13].

\section{Diagnosis and Treatment of BK Virus in Allogeneic and Autologous Bone Marrow Transplantation}

Many people who are infected with the BKV are asymptomatic, but in rare cases, it causes disease such as respiratory infection or fever, especially during early childhood. These are known as primary BK infections. After the first infection, polyomavirus can be latent in the kidneys, urothelium, and other organs, until the body undergoes some form of immunosuppression. In cases of immunosuppression, it persists for the life of the individual $[14,15,16]$.

The BK virus is rarely seen in autologous HSCT compared to allogeneic HSCT. In a study of 132 patients in which $19 \%$ of the patients underwent autologous 
transplantation, Forty-four patients (33\%) developed BK viremia at a median of 41 days (range, 9-91 days) after transplantation. Hemorrhagic cystitis was observed in 19 (14\%) of the 132.

HSCT recipients, at a median of 9 days (range, 1-84 days) after transplantation. Patients with hemorrhagic cystitis that occurred after platelet engraftment had higher levels of viremia than did patients without hemorrhagic cystitis (median, 9.7x10 (3) vs. 0 copies/mL; P=.008) and patients with hemorrhagic cystitis that occurred before platelet engraftment (median, 9.7x10(3) vs. 0 copies $/ \mathrm{mL}$; $\mathrm{P}=.0006)$. Univariate analysis of risk factors for any occurrence of $\mathrm{BK}$ viremia or for persistent $\mathrm{BK}$ viremia identified CMV seropositivity and the underlying disease as the only factors associated with BK viremia [14]. While it can emerge in the early or late phase of stem cell transplantation [8].

A grading system for severity of $\mathrm{HC}$ has been proposed by Droller et al. Grade I is defined as microscopic haematuria; grade II as macroscopic haematuria; grade III as macroscopic haematuria with clots; and grade IV as macroscopic haematuria with renal or bladder dysfunction [17]. In addition, viruses (BKV, JC virus, adenovirus, and cytomegalovirus [CMV]) and graft-versus-host disease (GVHD) are suspected in HC [18].

Reducing immunosuppression is the mainstay of therapy for HC due to BKV. Different interventions have been pursued, most commonly regress of tacrolimus or mycophenolate mofetil, but threshold values for drug doses have not yet been determined [5]. Many opioid analgesics, including acetaminophen, nonsteroidal antiinflammatory drugs, and even antispasmodic agents have a place in haemorrhagic cystitis therapy [6]. Phenazopyridine is prescribed for its local analgesic effects on the urinary tract. It is sometimes used in conjunction with an antibiotic or other anti-infective medication at the inception of treatment to help provide immediate symptomatic relief [7]. It has been reported in the literature that insertion of a large-bore three-way Foley's urethral catheter to decompress the bladder and saline solution irrigation of the bladder may slow or stop the bleeding. In some instances, cystoscopic clot evacuation may be necessary [8].

Cidofovir is becoming the drug of choice to treat viral $\mathrm{HC}$ in immunosuppressed patients. Cidofovir is an acyclic nucleotide phosphonate analogue of deoxycytosine monophosphate. It is active against most common viral pathogens and is licensed for the treatment of CMV retinitis. It has improved clinical outcomes and decreased viruria and viraemia in hematopoietic cell transplantation patients with BK-virus-associated HC. An important side effect of cidofovir is that it is a highly nephrotoxic drug. Gonzalez-Fraile et al. reported a single case with resolution of symptoms and BKV viruria with standard cidofovir treatment (5 mg/kg/day, fortnightly) [18]. Gorczynska et al. reported a study of 26 paediatric patients with HC due to human polyomavirus (human papillomavirus; 21 patients with BKV, one patient with JC virus, and four patients with adenovirus) who were given standard cidofovir dosing until resolution of symptoms (median, three treatments). Twenty-two children were treated with cidofovir with no significant toxicity. In all of the treated patients but one, the clinical symptoms were moderate and no HC-related death was observed. [19]. Held et al. reported a single case of standard cidofovir dosing (three doses) wherein the patient's haematuria resolved after 20 days and BKV viruria decreased after two doses of cidofovir [20]. Palandri et al. reported a single case in which there was no improvement after two doses of standard dose cidofovir; a superselective vesical artery embolisation was performed, which stopped the bleeding [21]. Kwon et al. reported their single-centre experience with treatment of BKV-associated haemorrhagic cystitis in paediatric HSCT recipients with standard dose cidofovir. They investigated the efficacy and safety of cidofovir therapy for patients with BKV-HC at a single institution and analysed the clinical management outcomes. They used cidofovir treatment in 12 patients (11 with probenecid and one without probenecid), and they found that clinical improvement was observed in all cases, with no HC-related death observed. Cidofovirrelated toxicity occurred in one patient and resolved spontaneously [22]. Cesaro et al. reported a new study regarding the relationship between clinical and BK virological response in patients with haemorrhagic cystitis treated with standard dose cidofovir. They evaluated, retrospectively, 32 cases of haemorrhagic cystitis after allogeneic HSCT that were treated with cidofovir. They determined that in patients with haemorrhagic cystitis, the response to cidofovir treatment is usually associated with a significant reduction of BK viraemia load. Nephrotoxicity related to cidofovir was observed in nine patients [23]. Savona et al. reported a study on low-dose cidofovir (1 $\mathrm{mg} / \mathrm{kg}$ of cidofovir weekly) treatment of BKV-associated haemorrhagic cystitis in which HSCT recipients with BKV-associated HC were treated with cidofovir. They reported that weekly low-dose cidofovir appears to be a safe treatment option for BKV-associated HC [24]. Hatakeyama et al. reported a single case with BKV and adenovirus. In their study, vidarabine was administered without effect, and a relatively low dose of cidofovir was efficacious. The adenovirus resolved after nine doses, and the BKV resolved after 14 doses [9]. Faraci et al. applied low-dose cidofovir without probenecid in seven children with BKV-associated haemorrhagic cystitis after HSCT, and clinical improvement was observed in all cases. The authors did not observe adverse events, although a significant reduction in urinary viral load was observed two weeks after the end of cidofovir in five out of six patients who completed the treatment [25]. Araya et al. reported a study about intermediate-dose cidofovir (0.75$1.0 \mathrm{mg} / \mathrm{kg} /$ dose) without probenecid in the treatment of BKV allograft nephropathy. The authors suggested that intermediate-dose cidofovir without probenecid, used judiciously, is not associated with additional nephrotoxicity, and it may provide an additional treatment alternative [26].

Leflunomide is a member of the malononitrilamide class of drugs, an immunosuppressive that is licensed for rheumatoid arthritis. Leflunomide has antiviral activity in vitro against $\mathrm{BKV}, \mathrm{CMV}$, and herpes simplex. It reduces the BK viral load in the blood and urine of renal transplant patients with BK nephropathy [10]. Liacini et al. reported a study about anti-BK-virus mechanisms of sirolimus and leflunomide alone and in combination, and they decided that combination therapy might reduce BK pathogenesis while maintaining appropriate transplant immunosuppression [27]. Chen et al. reported a study wherein leflunomide was used with allogeneic HSCT. Fourteen patients were treated with oral leflunomide, and efficacy was evaluated 
on day 20. Seven patients achieved complete remission, five patients achieved partial remission, and two patients had more than a 1-log reduction in urinary BKV-DNA loads. No significant toxicity was observed. The authors suggested that leflunomide might be a potentially effective medication for treating $\mathrm{HC}$ due to BKV [28].

Limited data is available regarding the efficacy of IVIG in patients with BK nephropathy [29]. Lekakis et al. reported a case wherein leflunomide and cidofovir were used at different times, both in combination with IVIG. In this study, both treatments were effective in reducing the BK viral load [30]. Anyaegbu et al. applied IVIG (2g/kg/day) to four patients as a treatment for BK viraemia and nephropathy in paediatric renal transplant recipients, and they found that IVIG seemed to be an effective treatment for persistent BKV after immunosuppression reduction [31].

Ciprofloxacin is a second-generation fluoroquinolone antibiotic. The efficacy of ciprofloxacin was best reported in a study of 68 HSCT patients; the data from that study support a role for ciprofloxacin in the prevention of BK viraemia [11]. Cekmen et al. reported the case of a 21year-old male patient who developed BKV nephropathy after renal transplantation. In an assessment of treatment with ciprofloxacin for six months, it was observed that the drug reduced the viral load and improved the clinical findings [32]. Wojciechowski et al. reported a study about ciprofloxacin prophylaxis in kidney transplant recipients. They compared the impact of a change in antibiotic prophylaxis practice from no BKV prophylaxis to BKV prophylaxis with ciprofloxacin $250 \mathrm{mg}$ twice daily for 30 days on the rate of BKV infection during the first 12 months after kidney transplantation. The authors determined that thirty-day ciprofloxacin prophylaxis in kidney transplant recipients was associated with a lower rate of BKV infection at three months, but not at 12 months. The long-term effectiveness and optimal duration of fluoroquinolone prophylaxis against BKV infection remain unknown [33].

Hyperbaric oxygen therapy has been used broadly in hypoxic tissues in an effort to induce angiogenesis and prompt healing, and it can be used successfully in the treatment of refractory HC in HSCT. Hughes reported a case of HC that occurred after autologous peripheral blood HSCT for multiple myeloma. The patient received cyclophosphamide and busulfan and contracted BK and adenovirus. The haemorrhage was refractory to multiple conventional treatments, but it resolved after a course of hyperbaric oxygen [12]. Savva-Bordalo et al. reported a study regarding the clinical effectiveness of hyperbaric oxygen therapy. They evaluated the effectiveness of hyperbaric oxygen therapy in 16 patients with HC after allogeneic HSCT, and 15 patients (94\%) showed complete resolution of haematuria [34]. Focosi et al. reported the study of a patient with severe BKV-associated haemorrhagic cystitis who did not respond to intravenous cidofovir. Overt haematuria successfully resolved after a few days on hyperbaric oxygen and intravesical instillations of cidofovir [35].

BK polyomavirus reactivation associated with a failure of T-cell immunity is associated with haemorrhagic cystitis in hematopoietic stem cell transplant recipients. The infusion of BKV-specific $\mathrm{T}$ cells could potentially reconstitute functional $\mathrm{BKV}$ immunity and reduce the clinical complications of BKV infection [13]. Blyth et al. reported that possible clinical uses for BKV-specific $\mathrm{T}$ cells generated using this method include the immune reconstitution of post-hemopoietic stem-cell transplantation or prophylaxis and treatment of immune deficiency in renal transplant recipients [36].

\section{Conclusion}

Although the role of the BKV in the aetiology of $\mathrm{HC}$ is more common in allogeneic HSCT patients, its frequency is not exactly known in autologous HSCT patients. More studies are required to determine the frequency of BKV in HC with autologous HSCT. The roles and success of the drugs used in the treatment of the BKV are unclear. Lowdose cidofovir appears to be less nephrotoxic than standard dose cidofovir. Leflunomide's use requires randomised controlled trials. BKV-specific T cells might prove to be the most optimal therapy.

\section{Competing Interests}

The authors declare that they have no competing interests.

\section{Authors' Contributions}

This report reflects the opinions of the authors and does not represent the official position of any institution or sponsor. IB was responsible for reviewing previous research, journal hand-searching, and drafting the report. MAE, MK, EB, FY and IN contributed to the final draft of the manuscript and analysis of relevant data. IK and EK were responsible for project coordination. All authors read and approved the final manuscript.

\section{Abbreviations}

$\begin{array}{ll}\text { Graft-versus-host disease } & \text { GVHD } \\ \text { Cytomegalovirus } & \text { CMV } \\ \text { Polymerase chain reaction } & \text { PCR } \\ \text { Hematopoietic stem cell transplantation } & \text { HSCT } \\ \text { Busulfan-Cyclophosphamide } & \text { BU-CY } \\ \text { International normalized ratio } & \text { INR } \\ \text { Activated partial thromboplastin time } & \text { APTT } \\ \text { Intravenous immune globulin } & \text { IVIG } \\ \text { BK virus } & \text { BKV } \\ \text { Hemorrhagic cystitis } & \text { HC } \\ \text { Acute myeloid leukaemia } & \text { AML } \\ \text { Microliter } & \mu l\end{array}$

\section{References}

[1] Gardner S.D., Field A.M., Coleman D.V., Hulme B. 'New human papovavirus (BK) isolated from urine after renal transplantation. Lancet 1971'; 1(7712):1253-1257.

[2] Gupta G, Shapiro R, Thai N., Randhawa P,S., Vats A.. 'Low incidence of BK virus nephropathy after simultaneous kidney pancreas transplantation'. Transplantation 2006; 82(3): 382-388.

[3] Sanchez-Pinto L.N., Laskin B.L., Jodele S.,Hummel T.R., Yin H.J., Goebel J. 'BK virus nephropathy in a pediatric autologous 
stem-cell transplant recipient.' Pediatr Blood Cancer 2011; 56(3): 495-497.

[4] Bista B.R., Ishwad C., Wadowsky R.M., Manna P.,Randhawa P.S., Gupta G., Adhikari M., Tyagi R., Gasper G., Vats A., 'Development of a loop-mediated isothermal amplification assay for rapid detection of BK virus. J Clin Microbiol '2007; 45(5): 1581-1587.

[5] Schaub S., Hirsch H.H., Dickenmann M., Steiger J., Mihatsch M.J., Hopfer H., Mayr M.,. 'Reducing immunosuppression preserves allograft function in presumptive and definitive polyomavirus-associated nephropathy. Am J Transplant'. 2010; 10(12): 2615-2623.

[6] Rummans T.A., Nonopioid agents for treatment of acute and subacute pain. Mayo Clin Proc 1994; 69(5): 481-490.

[7] Pergialiotis V., Arnos P., Mavros M.N., Pitsouni E., Athanasiou S., Falagas M.E., 'Urinary tract analgesics for the treatment of patients with acute cystitis: where is the clinical evidence? Expert Rev Anti Infect Ther' 2012; 10(8): 875-879.

[8] Manikandan R., Kumar S., Dorairajan L.N., Hemorrhagic cystitis: 'A challenge to the urologist. Indian J Urol' 2010; 26(2): 159-166.

[9] Hatakeyama N., Suzuki N., Kudoh T., Hori T., Mizue N., Tsutsumi H., ' Successful cidofovir treatment of adenovirusassociated hemorrhagic cystitis and renal dysfunction after allogenic bone marrow transplant.' Pediatr Infect Dis J 2003; 22(10): 928-929.

[10] Dropulic L.K., Jones R.J., ! Polyomavirus BK infection in blood and marrow transplant recipients. Bone Marrow Transplant '2008; 41(1): 11-18.

[11] Leung A.Y., Chan M.T., Yuen K.Y., Cheng V.C., Chan K.H., Wong C.L., Liang R., Lie A.K., Kwong Y.L., ' Ciprofloxacin decreased polyoma BK virus load in patients who underwent allogeneic hematopoietic stem cell transplantation.' Clin Infect Dis 2005; 40(4): 528-537.

[12] Hughes A.J., Schwarer A.P., Millar I.L., ' Hyperbaric oxygen in the treatment of refractory hemorrhagic cystitis. Bone Marrow Transplant '1998; 22(6): 585-586.

[13] Zhou W., Sharma M., Martinez J., Srivastava T., Diamond D.J., Knowles W., Lacey S.F., 'Functional characterization of BK virus-specific CD4+ $\mathrm{T}$ cells with cytotoxic potential in seropositive adults'. Viral Immunol 2007; 20(3): 379-388.

[14] Erard V., Storer B., Corey L., Nolkamper J.,.Huang M.L., Limaye A., Boeckh M., ' BK virus infection in hematopoietic stem cell transplant recipients: frequency, risk factors, and association with postengraftment hemorrhagic cystitis'. Clin Infect Dis 2004; 39(12): 1861-1865

[15] Giraud G., Bogdanovic G., Priftakis P., Remberger M., Svahn B.M., Barkholt L., Ringden O.,Winiarski J., Ljungman P., Dalianis T.,' The incidence of hemorrhagic cystitis and BK-viruria in allogeneic hematopoietic stem cell recipients according to intensity of the conditioning regimen. Haematologica'. 2006; 91: 401-404.

[16] Goudsmit J., Wertheim-van Dillen P., Van Strien A., Van der Noordaa J., 'The role of BK virus in acute respiratory tract disease and the presence of BKV DNA in tonsils.' J Med Virol 1982; 10(2): 91-99.

[17] Droller M.J., Saral R., Santos G.,' Prevention of cyclophosphamide- induced hemorrhagic cystitis.' Urology.1982; 20(3): 256-258.

[18] González-Fraile M.I., Cañizo C., Caballero Hernandez R., Vazguez L., Lopez C., Izarra A., Arroyo JL., de la Loma A., Otero MJ., San miguel JF., 'Cidofovir treatment of human polyomavirus-associated acute haemorrhagic cystitis.' Transpl Infect Dis 2001; 3(1): 44-46.

[19] Gorczynska E., Turkiewicz D., Rybka K., Toporski J., Kalwak K., Dyla A., Szczyra Z., Chybicka A., 'Incidence, clinical outcome, and management of virus-induced hemorrhagic cystitis in children and adolescents after allogeneic hematopoietic cell transplantation’. Biol Blood Marrow Transplant 2005;11(10): 797804.

[20] Held T.K., Biel S.S., Nitsche A., Kurth A., Chen S., GelderbLom H.R., Siegert W., 'Treatment of BK virus-associated hemorrhagic cystitis and simultaneous CMV reactivation with cidofovir. Bone Marrow Transplant '2000; 26(3): 347-350.
[21] Palandri F., Bonifazi F., Rossi C., Falcioni S., Arpinati M., Giannini M.B., Ansaloni F., Bandini G., Baccarani M., 'Successful treatment of severe hemorrhagic cystitis with selective vesical artery embolization. Bone Marrow Transplant '2005; 35(5): 529-530.

[22] Kwon H.J, Kang J.H, Lee J.W., Chung N.G., Kim H.K., Cho B., 'Treatment of BK virus-associated hemorrhagic cystitis in pediatric hematopoietic stem cell transplant recipients with cidofovir: a single-center experience'. Transpl Infect Dis. 2013; 15(6): 569-574.

[23] Cesaro S., Pillon M., Tridello G.. 'Relationship between clinical and $\mathrm{BK}$ virological response in patients with late hemorrhagic cystitis treated with cidofovir: a retrospective study from the European Group for Blood and Marrow Transplantation. Bone Marrow Transplant' 2013; 48(6): 809-813.

[24] Savona M.R., Newton D., Frame D., Levine J.E., Mineishi S., Kaul D.R., ' Low-dose cidofovir treatment of BK virus-associated hemorrhagic cystitis in recipients of hematopoietic stem cell transplant. Bone Marrow Transplant '2007; 39(12): 783-787.

[25] Faraci M., Cuzzubbo D., Lanino E., Di Marco E., Cirillo C., Dallorso S., Morreale G., Moroni C., Castagnola E., ‘ Low dosage cidofovir without probenecid as treatment for BK virus hamorrhagic cystitis after hemopoietic stem cell transplant'. Pediatr Infect Dis J 2009; 28(1): 55-57.

[26] Araya C.E., Lew J.F., Fennell R.S., 3rd, Neiberger R.E., Dharnidharka V.R., Intermediate-dose cidofovir without probenecid in the treatment of BK virus allograft nephropathy'. Pediatr Transplant 2006; 10(1): 32-37.

[27] Liacini A., Seamone M.E., Muruve D.A., Tibbles L.A., 'Anti-BK virus mechanisms of sirolimus and leflunomide alone and in combination: toward a new therapy for BK virus infection. Transplantation '2010; 90(12): 1450-1457.

[28] Chen X.C., Liu T., Li J.J., He C., Meng W.T., Huang R.,’ Efficacy and safety of leflunomide for the treatment of BK virus-associated hemorrhagic cystitis in allogeneic hematopoietic stem cell transplantation recipients’. Acta Haematol 2013; 130(1): 52-56.

[29] Sener A., House A.A., Jevnikar A.M., Boudville N., Mcalister V.C., Muirhead N., Rehman F., Luke P.P., 'Intravenous immunoglobulin as a treatment for BK virus associated nephropathy: one-year follow-up of renal allograft recipients'. Transplantation 2006; 81(1): 117-120.

[30] Lekakis L.J., Macrinici V., Baraboutis I.G., Mitchell B., Howard D.S., 'BK virus nephropathy after allogeneic stem cell transplantation: a case report and literature review'. Am J Hematol 2009; 84(4): 243-246.

[31] Anyaegbu E.I., Almond P.S., Milligan T., Allen W.R., Gharaybeh S., Al-Akash S.I. 'Intravenous immunoglobulin therapy in the treatment of BK viremia and nephropathy in pediatric renal transplant recipients'. Pediatr Transplant 2012; 16(1): 19-24.

[32] Cekmen M.B., Bakirdoven S., Sayan M., Yılmaz A.,' BK virus nephropathy developing after renal transplantation and its treatment with ciprofloxacin: a case report'. Transplant Proc 2012; 44(10): 3044-3047.

[33] Wojciechowski D., Chanda R., Chandran S., Lee B., Webber A., Macaraig M., Tomlanovich S., Vincenti F., 'Ciprofloxacin prophylaxis in kidney transplant recipients reduces BK virus infection at 3 months but not at 1 year'. Transplantation 2012:15; 94(11): 1117-1123.

[34] Savva-Bordalo J., Pinho Vaz C., Sousa M.,. 'Clinical effectiveness of hyperbaric oxygen therapy for BK-virus-associated hemorrhagic cystitis after allogeneic bone marrow transplantation'. Bone Marrow Transplant 2012; 47(8): 1095-1098.

[35] Focosi D., Maggi F., Pistolesi D., Benedetti E., Papineschi F., Galimberti S., Ceccherini-Nelli L., Petrini M., 'Hyperbaric oxygen therapy in BKV-associated hemorrhagic cystitis refractory to intravenous and intravesical cidofovir: case report and review of literature.' Leuk Res 2009; 33(4): 556-560.

[36] Blyth E., Clancy L., Simms R., Gaundar S., O’Connell P., Mickletwaite K., Gottlieb DJ., 'BK virus-specific T cells for use in cellular therapy show specificity to multiple antigens and polyfunctional cytokine responses'. Transplantation. 2011; 92(10): 1077-1084. 